\title{
SYNTHESIS GROWTH AND PROPERTIES OF AN ORGANIC NONLINEAR OPTICAL CRYSTAL L HISTIDINIUM MALEATE (LHM)
}

\author{
L.Mariappan and R.Pavithra \\ PG and Research Department of Physics \\ L.N.Government College (Autonomous), Ponneri -601204,Tamilnadu, India
}

\begin{abstract}
The objective of this study is to grow and to characterize the L- Histidinium Maleate (LHM) crystal and to learn its suitability in modern Non-Linear Optics. This organic crystal grown by slow evaporation method has shown amazing optical performances and satisfactory spectral impressions in electronic and vibrational spectra. The Powder X-Ray Diffraction (PXRD) pattern confirmed the crystalinity of the synthesized LHM crystal. The Second Harmonic Generation (SHG) of LHM confirmed its Non-Linear Optical (NLO) performance.

Keywords : X-Ray Diffraction, Thermal Property, NLO material

1. Introduction

The synthesis ofnew organic crystals having nonlinear optical property is essential for chemistry and physics scholars due to their potential applications in the area of telecommunications, signal processing, optical switching and data storage technology [1-5].

L-Histidinepossessimidazole moiety and high optical nonlinearity compared to other amino acids [6-8]. In the present study, a systematic examination has been carried out on the synthesis and growth of L-Histidinium Maleate. The grown crystal was subjected to various characterization techniques, such as single crystal and powder X-ray diffraction, optical absorption, Fourier Transform Infrared Spectroscopy, Conductivity, Photoluminescence and Second harmonic generation test.

\section{Experimental}

An equimolar quantity of L-Histidineand maleic acid was dissolved in a mixed solvent of ethanol and water and the solution was stirred well for

\section{Results and Discussion}

\subsection{Single Crystal X-Ray Diffraction}

The single crystal X-ray diffraction has been carried out using Enraf-Nonius CAD-4 diffractometer with $\mathrm{CuK} \alpha$ radiation $(\lambda=1.5418$ $\AA$ ). L-Histidinium Maleate crystal belongs to the triclinic system. The cell parameters are $\mathrm{a}=7.22$ $\AA, \mathrm{b}=9.89 \AA, \mathrm{c}=12.94 \AA$ and volume $\mathrm{V}=845$ $\mathrm{A}^{3}$,

\subsection{Powder X-Ray Diffraction}

LHM was subjected to powder X-ray diffraction analysis using a Reich-SeifertX-ray diffractometer with $\mathrm{CuK} \alpha \quad(\lambda=1.5418 \AA)$ radiation. The sample was scanned over the range of $10^{\circ}-60^{\circ}$ at a rate of $1 \% \mathrm{~min}$. The X-ray diffraction pattern ofL-Histidinium Maleate is shown in Fig.2. The X-ray diffraction peaks were indexed for the lattice and the prominent peaks obtained from the powder parametersX-ray diffraction confirm the crystallinity of the grown crystals.
\end{abstract} about $1 \mathrm{~h}$ using a magnetic stirrer to ensure homogeneous concentration over entirevolume of the solution. Theprepared solution was allowed to evaporate at room temperature. The quality of the material was improved by successive recrystallization processes.

Transparent crystals were harvested in a period of 12 days. The photograph of the as-grown crystals of L-Histidinium Maleate is shown in Fig.1.

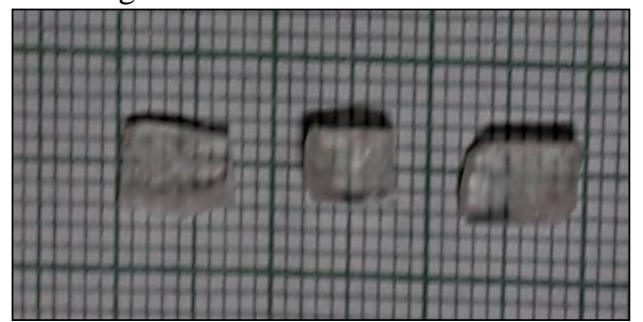

Fig.1 As grown single crystals of L-Histidinium Maleate

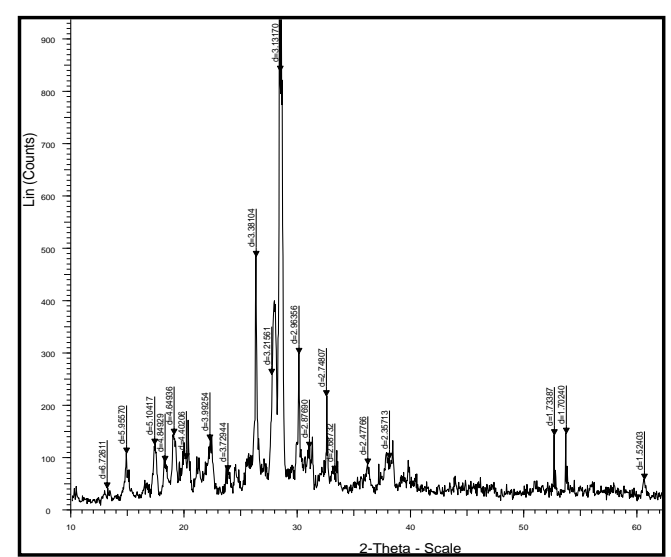

Fig. 2 X-ray Diffraction pattern of L-Histidinium Maleate 


\subsection{UV-VIS-NIR Absorption Spectrum}

The grown single crystal was subjected to UV-vis-NIR studies at room temperature in the wavelength range from 200 to $1000 \mathrm{~nm}$ using a Shimadzu UV-vis spectrophotometer and the recorded spectrum is shown in Fig.3. From the absorption spectrum, it was found that the lower cut-off wavelength is $285 \mathrm{~nm}$. The crystal is found to be transparent in the region of 400-800 $\mathrm{nm}$ which is an essential parameter for frequency doubling applications [9].

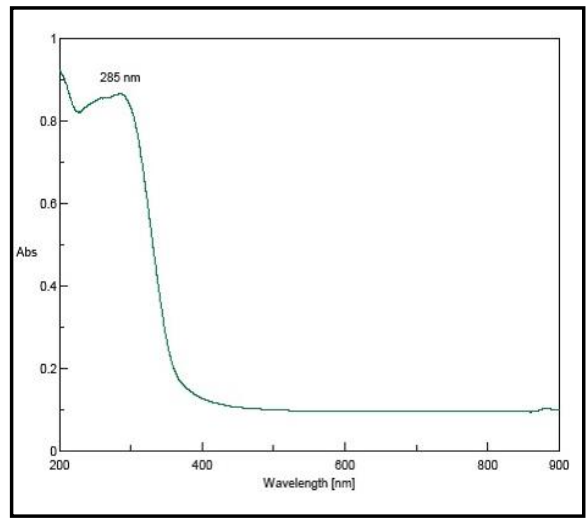

Fig. 3Optical Absorption Spectrum of L-Histidinium Maleate

\subsection{FTIR Analysis}

The FTIR spectrum of LHistidinium Maleate was recorded using PerkinElmer Spectrophotometer in the mid IR region of $4000 \mathrm{~cm}^{-1}$ to $600 \mathrm{~cm}^{-1}$ by $\mathrm{KBr}$ pellet technique is given in Fig.4.A peak observed at $3374 \mathrm{~cm}^{-1}$ corresponds to the $\mathrm{NH}_{2}$ stretching vibration. The broad absorption band in the region of $3055 \mathrm{~cm}^{-1}$ is due the $\mathrm{O}-\mathrm{H}$ stretching vibration. A bandat $2871 \mathrm{~cm}^{-1}$ is due to the $\mathrm{C}-\mathrm{H}$ functional group stretching of the LHM molecule. $\mathrm{C}=\mathrm{O}$ asymmetric stretching vibrations of LHM is observed in the region of $1704 \mathrm{~cm}^{-1}$.

Symmetric stretching vibrations of $\mathrm{C}=\mathrm{O}$ functional group is observed in the region of $1564 \mathrm{~cm}^{-1}$. Bands observed in the region of $1454 \mathrm{~cm}^{-1}$ and $1429 \mathrm{~cm}^{-1}$ are due to $\mathrm{H}-\mathrm{O}-\mathrm{H}$ deformations [10].FTIR absorptions at $1350 \mathrm{~cm}^{-1}$ and $1254 \mathrm{~cm}^{-1}$ are the cause of asymmetric and symmetric $\mathrm{C}-\mathrm{N}$ stretching vibrations. The $\mathrm{C}-\mathrm{O}$ functional groups of LHM shows IR absorptions at $1214 \mathrm{~cm}^{-1}$ and $1176 \mathrm{~cm}^{-1}$. The absorption due to in-plane bending of $\mathrm{C}-\mathrm{N}$ functional group in FTIR spectrum is seen at $1082 \mathrm{~cm}^{-1}$. The in-plane bending of $\mathrm{C}-\mathrm{O}$ is observed at $976 \mathrm{~cm}^{-1}$. A band at $880 \mathrm{~cm}^{-1}$ is due to the absorption of $\mathrm{C}-\mathrm{H}$ in plane bending. The bands at $780 \mathrm{~cm}^{-1}, 700 \mathrm{~cm}^{-1}$ and $630 \mathrm{~cm}^{-1}$ are due the out-of plane deformations of $\mathrm{C}-\mathrm{O}$ and $\mathrm{C}-\mathrm{H}$ functional groups.

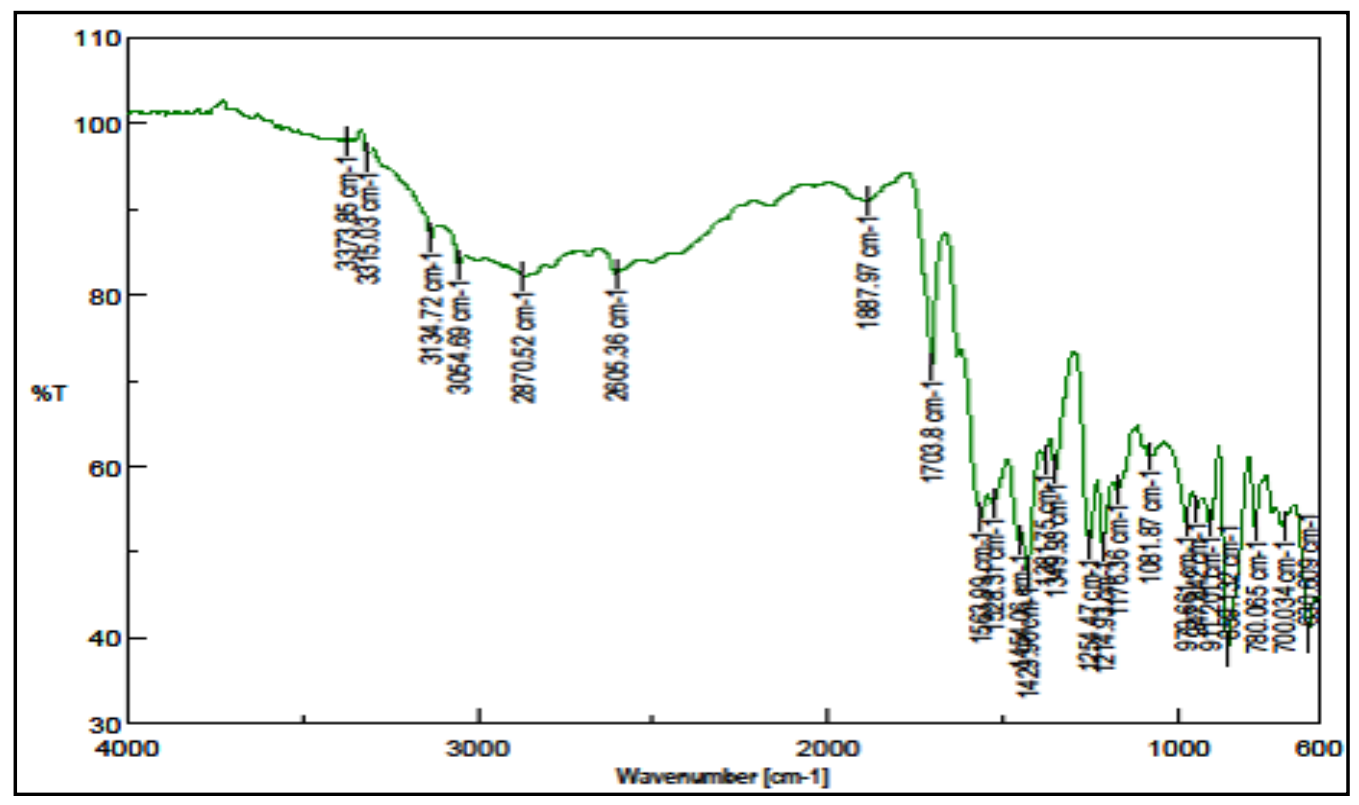

Fig. 4 FTIR Spectrum of L-Histdinium Maleate 


\subsection{Thermal Analysis}

The thermogravimetric (TG) and differential thermal analyses (DTA) provide information about phase transition, water of crystallization and different stages of decomposition of the crystal system. The thermal behavior of the material was studied using ZETZSCH-Geratebau $\mathrm{GmbH}$ thermal analyzer. The sample was heated in a nitrogen atmosphere in an alumina crucible at the rate of $10^{\circ} \mathrm{C} / \mathrm{min}$. The TGA and DTA thermogram of the grown crystal is shown in Fig. 5.

TGA shows that the material starts to decompose at $101^{\circ} \mathrm{C}$ followed by weight loss at $132^{\circ} \mathrm{C}, 185^{\circ} \mathrm{C}$ and $205^{\circ} \mathrm{C}$. The weight losses are due to the volatility of the residual organic functional groups.A sharp endothermic peak at $101.6^{\circ} \mathrm{C}$ indicates the melting point of the material.From TG-DTA it was found that the material is thermally stable up to $101.6^{\circ} \mathrm{C}$.

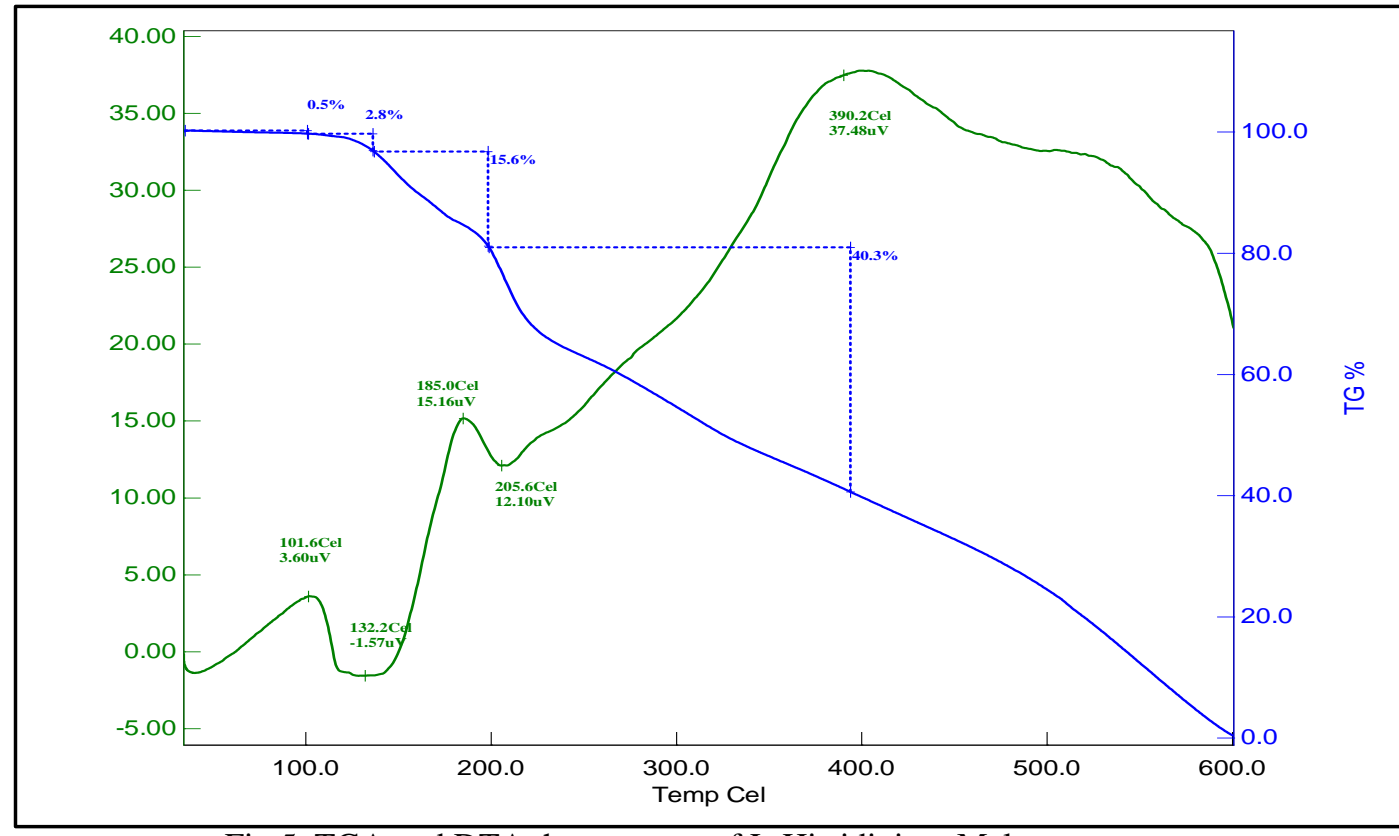

Fig.5 TGA and DTA thermogram of L-Histidinium Maleate

\subsection{Photoconductivity Measurement}

Photoconductivity plot of the L-

Histidinium Maleate crystal is shown in Fig. 6. The plot shows that the photo current is increasing with the voltage applied and is found to be less than that of the dark current. This shows that the grown crystal exhibit negative photo conductivity [11].

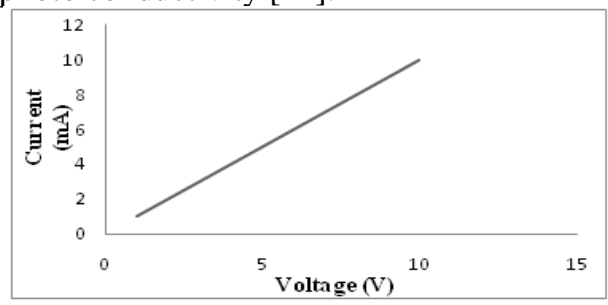

Fig. 6 PhotoConductivity of L-Histidinium Maleate

\subsection{Photoluminescence Studies}

Photoluminescence study is a nondestructive method of analysing the electronic structure of materials. The photoluminescencespectrum of the grown crystal was recorded in the range from 200 to $500 \mathrm{~nm}$ is shown in Fig. 7. The maximum intensity peak at $385 \mathrm{~nm}$ corresponds to near band-edge excitons of as-growncrystals. Hence the grown crystals can be useful for UV filters and optoelectronic laserdevices.

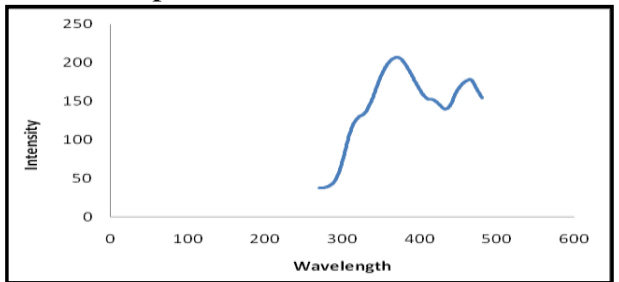

Fig.7 Photoluminescence spectrum of L-Histidinium Maleate www.trendytechjournals.com 


\subsection{Second Harmonic Generation}

SHG of the material was found by Kurtz-powder technique[12]. The second harmonic signal generated in the crystalline sample was confirmed from the emission of green radiation $(\lambda=532 \mathrm{~nm})$ from the crystal. The KDP sample was used as the reference material and the second harmonic generation intensity of L-Histidinium Maleate was found to be 1.5 times that of KDP.

\section{Conclusion}

Single crystals of LHistidiniumMaleatewere grown by the solvent evaporation technique in an aqueous solution at room temperature. Powder X-ray diffraction studies confirm the crystallinity of the grown crystal. The crystal belongs to the triclinic system. The optical absorption spectrum shows that the transparency cut off wavelength is $285 \mathrm{~nm}$. Thematerial is thermally stable up to $101.6^{\circ} \mathrm{C}$.The crystal exhibit negative photo conductivity.Photoluminescence study was carried out. The second harmonic generation intensity was found to be 1.5 times higher than that of KDP.

\section{References}

1.G. Xing, M. Jiang, Z. Shao, D. Xu, Chin. J. Lasers 14 (1987) 357.

2.S. Velsko, Laser Program Annual Report, Lawrence UCRL-JC 105000,

Lawrence Livermore National Laboratory, Livermore, CA, 1990.

3.L.F. Warren, Electronic materials our future, in: R.E. Allred, R.J. Martinez,

K.B. Wischmann (Eds.), Proceedings of the Fourth International Sample
Electronics Conference, Society for the Advancement of Material and Process Engineering, Covina, CA, 1990, Vol.4, p. 388.

4.P.R. Newman, L.F. Warren, P. Cunnigham, T.Y. Chang, D.E. Copper, G.L.

Burdge, P. Polakdingels, C.K. LoweMa, in: C.Y. Chiang, P.M. Chaikan, D.O. Cowan (Eds.), Advanced Organic Solid State Materials, Materials Research Society Symposium Proceedings, Materials Research Society, Pittsburg, PA,1990,Vol.173, p. 557.

5.P.M. Ushasree, R. Jayavel, C. Subramanian, P. Ramasamy, Bull. Electrochem.14 (1998) 407.

6.Buckley, H.E., "Crystal Growth”, Wiley, New York, 1951.

7.Chemla, D. S., Zyss, J., Liao, P. F. and Kelley, P. "Quantum Electronics

Principles and Applications", Academic, New

York, 1987.

8.Meir, U., Bosch, M., Boshard, C. and Gunter,

P. "DAST a high optical

non linearity organic crystal", Synth. Met., Vol.

109, No. 1-3, pp. 19-.22, 2000.

9.Roshan, S. A., Joseph, C., and Ittyachen, M. A. "Growth and characterization of a new metalorganic crystal: potassium thiourea bromide", Mater. Lett.,Vol. 49, No. 5, pp. 299-302, 2001.

10.Dhanavel, S., Stephen, A., and Samuel Asirvatham, P., "Spectroscopic investigation, HOMO-LUMO and NLO studies on Lhistidinium maleate based on DFT approach", AIP Conference Proceedings, Vol. 1832, pp. 090003-1 - 090003-3, 2017.

11.Arumugam, J., Suresh, N., Selvapandiyan, M., Sudhakar, S., Prasath, M., "Effect of $\mathrm{NaCl}$ on the properties of Sulphamic Acid Single Crystals", Heliyon, Vol. 5, pp. 1-3, 2019.

12. Kurtz, S. K. and Perry, T. T. J. Appl. Phys. 39 (1968), 3798-3813 